\title{
The Extent of Medication-Related Hospital Admissions in Australia: A Review from 1988 to 2021
}

\author{
Renly $\operatorname{Lim}^{1}$ (1) $\cdot$ Lisa M. Kalisch Ellett ${ }^{1} \cdot$ Susan Semple ${ }^{1} \cdot$ Elizabeth E. Roughead $^{1}$
}

Accepted: 22 December 2021 / Published online: 28 January 2022

(c) The Author(s) 2022

\begin{abstract}
Introduction Medication-related problems often lead to patient harm. This paper aims to review the Australian literature to determine the overall incidence, severity and preventability of medication-related hospital admissions, as well as providing a national estimate on their extent and cost.

Methods The first part of the paper includes a literature search to identify studies that provided estimates of medicationrelated problems that caused hospital admissions. Incidence of medication-related hospital admissions, type of medicationrelated problem contributing to admission (e.g. adverse medicine reaction) and method used to estimate incidence (e.g. chart review) were extracted. Data on severity and preventability of the admissions were extracted where available. The second part of the paper involves use of methodological triangulation to estimate the extent and cost of medication-related hospital admission. Median estimates used to assess medication-related hospital admissions and the 2019-2020 national hospital admissions data were used to calculate the national estimate on the extent of medication-related hospital admission. Costs were also estimated.

Results Seventeen studies provided estimates on the extent of medication-related hospital admissions as assessed using medication chart review. The median incidence of $2.5 \%$ (interquartile range [IQR] $0.6 \%$ ) as a proportion of all hospital admissions suggests 275,000 hospital admissions annually in Australia are medication related. The median incidence of 9\% (IQR $3.9 \%$ ) of emergency admissions suggests that 270,000 admissions annually are medication related. Eight studies provided estimates of the extent of medication-related hospital admissions identified from administrative health data; the median incidence of $1.7 \%$ with an under-reporting rate of $82 \%$ suggests 280,000 hospital admissions annually are medication related. Triangulation of results suggests that at least 250,000 hospital admissions annually in Australia are medication related, with an estimated cost of 1.4 billion Australian dollars (AUD\$). Five studies assessed severity, and nine studies assessed preventability. Preventability estimates suggest two-thirds of medication-related hospital admissions are potentially preventable.

Conclusions We estimated that 250,000 hospital admissions in Australia are medication related, with an annual cost of AUD $\$ 1.4$ billion to the healthcare system. Two-thirds of medication-related hospital admissions are potentially preventable.
\end{abstract}

\section{Introduction}

Medication use is the most common intervention in healthcare. In Australia, over 300 million prescriptions for medications are dispensed every year [1], with national survey estimates of self-report showing $70 \%$ of the general population and over $90 \%$ of older Australians have received at least one prescription in the last 12 months

Renly Lim

renly.lim@unisa.edu.au

1 Quality Use of Medicines and Pharmacy Research Centre, UniSA Clinical and Health Sciences, University of South Australia, GPO Box 2471, Adelaide, SA 5001, Australia

\section{Key Points}

Medication-related problems often lead to patient harm, yet many of these harms, including hospital admissions due to the medications, are preventable.

We estimated that 250,000 hospital admissions in Australia are medication related, with an annual cost of 1.4 billion Australian dollars to the healthcare system.

Two-thirds of medication-related hospital admissions are potentially preventable. 
[2]. In any 2-week period, almost one in two Australians (47\%) reported taking a medicine [2]. The estimated cost of medicines to Australians, including both prescription and over-the-counter medicines, is 23.4 billion Australian dollars (AUD\$) annually [3]. This accounts for approximately $12 \%$ of annual healthcare expenditure (AUD $\$ 196$ billion) in Australia [3].

The high frequency of medication use means that problems with medications are also very common. Examples of medication-related problems include adverse medicine events, adverse medicine reactions, inappropriate medicine selection, under- or overdosing, medication use without an indication, medicine-medicine interactions and untreated indications [4]. Adverse medicine event (or adverse drug event) refers to harms that occur as a result of use of a medication, but which may not necessarily have a causal relationship with the medication. Adverse medicine reaction (or adverse drug reaction) is a subset of adverse medicine events, where the harm is directly caused by administration of a medication [5]. In Australia, about one in five people are identified as suffering an adverse medication event at the time they receive a Home Medicines Review [6], an Australian government-funded service where a pharmacist visits the patient in the home to undertake a comprehensive medication review [7]. On average, four medication-related problems are detected for each person at the time of the Home Medicines Review [7].

Medication-related problems often lead to patient harm, yet many of these harms, including hospital admissions due to the medications, are preventable [8,9]. In our previous reports published over the last 2 decades, we consistently found that medication safety in the community and acute setting is a major challenge to the Australian healthcare system [10-12]. The current paper provides an update on the extent of medication-related hospital admission in Australia, by consolidating new evidence with our previous findings [10-12]. The aim of the paper is twofold: (1) to review the Australian literature published between 1988 and 2021 to determine the overall incidence, severity and preventability of medication-related hospital admissions and (2) to triangulate findings on the incidence to provide a national estimate on the extent and cost of medicationrelated hospital admissions in Australia.

\section{Methods}

\subsection{Search Strategy}

The paper updates work previously undertaken on medication-related hospital admissions in Australia [11, 12] to include literature published between 2013 and July 2021. A literature search was performed in Medline, PubMed, Embase, Ovid Emcare, Joanna Briggs Institute and International Pharmaceutical Abstracts to identify studies conducted in the acute setting in Australia. Search terms related to adverse drug events, adverse drug reactions, medication-related problems, medication error, hospital admissions, incidence and prevalence were used (see the electronic supplementary material). The search was restricted to studies conducted in Australia. The reference lists of shortlisted papers were screened to identify other relevant papers. Two authors (RL and EER) screened all titles. Any disagreement was resolved by consensus among all study authors. No authors were contacted for additional information.

\subsection{Selection and Grouping of Studies}

We included studies that identified prevalence or incidence of medication-related problems causing hospital admissions assessed by chart review or by coding from administrative data, or a combination of these methods. Studies were grouped according to the method employed. Studies that used both methods were evaluated to determine the level of under-reporting from administrative data alone, assuming chart review by an independent panel was the gold standard.

Medication-related adverse events identified from administrative data can include events that contributed to hospital admission (i.e. identified at admission) or events that occurred during hospital stay. We used only incidence reported at admission to estimate the median incidence of medication-related hospital admission.

Studies providing estimates of incidents specific to only one type of medicine were excluded.

\subsection{Data Extraction}

Data extraction was performed by two authors (RL and EER). Data items that were extracted included author and year, number of patients, type of admission (e.g. emergency admission, geriatric admission), incidence of medication-related hospital admission, type of medication-related problem (e.g. adverse medicine reaction) and method used to estimate incidence (e.g. chart review). Data on severity and preventability of adverse medicine events associated with hospitalisation or admissions due to medication-related problems were extracted where available. 


\subsection{Methodological Triangulation}

To estimate the incidence and cost of medication-related hospital admissions nationally, the authors first categorised the included studies based on the method used in each study to estimate the incidence (e.g. chart review). Studies were also grouped by the denominator (e.g. all admissions, unplanned admissions only, geriatric admissions only). The median incidence for each group was determined for each of the categories. Using the annual number of hospital admissions in Australia (extracted from the Australian Institute of Health and Welfare, admission in 2019-2020, accessed 12 October 2021) [13] for each of the relevant groupings as the denominator, the median incidence was then used to calculate the estimated number of medication-related hospital admissions for each category. Using methodological triangulation [14], we then compared the estimates in each category to derive a conclusive national estimate on the extent of medicationrelated hospital admissions in Australia. The national estimate was also used to calculate the annual cost associated with medication-related hospital admissions. The cost per hospital stay in Australia was extracted from the Australian Institute of Health and Welfare [15].

Descriptive statistics were used to summarise the incidence of medication-related hospital admissions. Categorical variables were presented as counts and percentages. Where outliers were present, sensitivity analysis was conducted by removing the outliers and re-estimating the national estimate on the extent of medication-related hospital admissions. Outliers were defined using the Tukey method as values that were either below the 25 th percentile or above the 75 th percentile by greater than 1.5 times the interquartile range (IQR) [16].

\section{Results}

\subsection{Extent of Medication-Related Hospital Admissions}

\subsubsection{Extent of Medication-Related Hospital Admissions Assessed Using Chart Review}

Since our last review in 2013 [12], there have been only three new studies that have estimated the incidence of medication-related hospital admissions assessed using chart review: two studies in the emergency department and one in a geriatric population (Fig. 1; Table 1) [17-33]. Of the 17 separate studies in total, two studies estimated the rates of medication-related hospital admissions for all admissions $[17,18]$, four studies estimated the rates in the emergency department [19-22], three in medical wards [23-25], six in geriatric populations [26-31] and two in paediatric populations [32, 33].

Between 2 and 4\% (median 2.5\%, IQR $0.6 \%$ ) of all admissions were medication related, with rising estimates when sub-populations were studied. Six per cent to $16 \%$ (median 9\%, IQR 3.9\%) of admissions via the emergency department, $12-15 \%$ (median 12\%, IQR 1.8\%) of medical ward admissions, $15-38 \%$ (median $20.5 \%$, IQR $10.1 \%$ ) of geriatric admissions via emergency department and 3-4\% (median $3.5 \%$, IQR $0.5 \%$ ) of paediatric admissions were medication related (Fig. 1; Table 1). Adverse medicine reactions were the most common type of medicationrelated admissions.

There were 11 million hospital admissions in Australia in 2019-2020 [13]. The median incidence of medication-related admissions as a proportion of all hospital admissions (2.5\%) suggests that 275,000 hospital
Fig. 1 Percentage of medication-related hospital admissions in Australia as assessed using medication chart review (created by the authors)

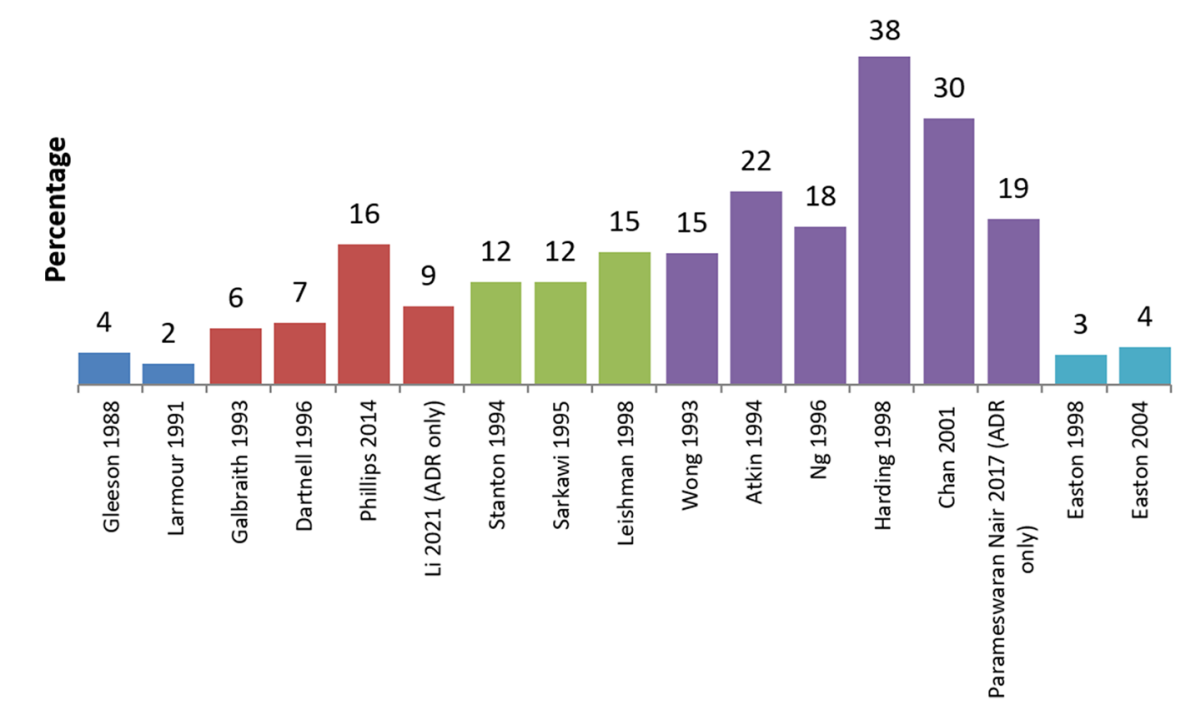

All admissions $\square$ Emergency Department $\square$ Medical Wards $\square$ Geriatric $\square$ Paediatric 
Table 1 Incidence of medication-related hospital admissions in Australia assessed using chart review (created by the authors)

\begin{tabular}{|c|c|c|c|c|c|c|}
\hline & \multirow{2}{*}{$\begin{array}{l}\text { Total admis- } \\
\text { sions reviewed }\end{array}$} & \multirow[t]{2}{*}{ Total medicine related } & \multicolumn{4}{|c|}{ Type of medicine-related admission } \\
\hline & & & $\begin{array}{l}\text { Adverse medi- } \\
\text { cine reaction }\end{array}$ & Non-compliance & Overdose & Other \\
\hline \multicolumn{7}{|l|}{ All hospital admissions assessed } \\
\hline Gleeson, 1988 [17] & 947 & $34(3.6 \%)$ & $34(3.6 \%)$ & N/A & N/A & N/A \\
\hline Larmour et al. $1991[18]$ & 5623 & $136(2.4 \%)$ & $90(1.6 \%)$ & $5(0.09 \%)$ & $40(0.7 \%)$ & $1(0.02 \%)$ \\
\hline \multicolumn{7}{|c|}{ Admissions via Emergency Department assessed } \\
\hline Galbraith 1993 [19] & 751 & $48(6.4 \%)$ & N/A & N/A & $7(0.9 \%)$ & N/A \\
\hline Dartnell et al. 1996 [20] & 965 & $68(7 \%)$ & $26(2.7 \%)$ & $15(1.6 \%)$ & $13(1.3 \%)$ & $14(1.5 \%)$ \\
\hline Phillips et al. 2014 [21] & 370 & $59(16 \%)$ & N/A & N/A & N/A & N/A \\
\hline Li et al. 2021 [22] & 5521 & $496(9 \%)$ & $496(9 \%)$ & N/A & N/A & N/A \\
\hline \multicolumn{7}{|l|}{ Admissions to Medical Wards assessed } \\
\hline Stanton et al. 1994 [24] & 691 & $81(11.7 \%)$ & $21 *(3 \%)$ & $10 *(1.4 \%)$ & $26 *(3.8 \%)$ & $11 *(1.6 \%)$ \\
\hline Sarkawi and Daud 1995 [23] & 419 & $49(11.7 \%)$ & $21(5 \%)$ & $12(2.9 \%)$ & $14(3.3 \%)$ & $2(0.5 \%)$ \\
\hline Leishman and Vial 1998 [25] & 217 & $33(15.2 \%)$ & $10(4.6 \%)$ & $8(3.7 \%)$ & $11(5.1 \%)$ & $4(1.8 \%)$ \\
\hline \multicolumn{7}{|c|}{ Geriatric admissions via emergency departments assessed } \\
\hline Wong et al. 1993 [26] & 541 & $81(15 \%)$ & $61(11.3 \%)$ & $19(3.5 \%)$ & $1(0.2 \%)$ & N/A \\
\hline Atkin et al. 1994 [30] & 217 & $48(22.1 \%)$ & $41(18.9 \%)$ & $5(2.3 \%)$ & $1(0.5 \%)$ & $1(0.5 \%)$ \\
\hline $\mathrm{Ng} 1996[31]$ & 172 & $31(18 \%)$ & $18(10.5 \%)$ & $5(2.9 \%)$ & $1(0.6 \%)$ & $7(4.1 \%)$ \\
\hline Harding 1998 [28] & 16 & $6(37.5 \%)$ & $4(25.0 \%)$ & $1(6.25 \%)$ & 0 & $1(6.25 \%)$ \\
\hline Chan et al. $2001[29]$ ( $\geq 75$ years) & 240 & $73(30.4 \%)$ & $32(13.3 \%)$ & $9(3.8 \%)$ & $1(0.42 \%)$ & $31(12.9 \%)$ \\
\hline $\begin{array}{l}\text { Parameswaran Nair et al. } 2017 \text { [27] } \\
>65 \text { years }\end{array}$ & 1008 & $191(18.9 \%)$ & $191(18.9 \%)$ & N/A & N/A & N/A \\
\hline \multicolumn{7}{|c|}{ Paediatric admissions assessed—medical only excluding oncology } \\
\hline Easton et al. 1998 [32] & 1682 & $58(3.4 \%)$ & $10(0.6 \%)$ & $29(1.7 \%)$ & $10(0.6 \%)$ & $9(0.5 \%)$ \\
\hline Easton et al. 2004 [33] & 2933 & $127(4.3 \%)$ & $29(1.0 \%)$ & $38(1.3 \%)$ & N/A & N/A \\
\hline
\end{tabular}

N/A Not available

"Total does not add up to 81 because study authors excluded 13 "possible" medication-related admissions from the analysis

admissions annually are medication related. There were 3 million emergency admissions in Australia [13]. The median incidence of $9 \%$ of emergency admissions suggests that 270,000 admissions annually are medication related. Approximately 1.3 million emergency admissions involve older people [13]. The median incidence of $20.5 \%$ of geriatric admissions via the emergency department being medication related suggests that 260,000 hospital admissions in older people annually are medication related. Sensitivity analysis excluding the outlier study [28] in the geriatric population decreased the median incidence to $18.5 \%$ (IQR 4\%), suggesting 240,000 hospital admissions in the geriatric population are medication related.

\subsubsection{Extent of Medication-Related Hospital Admissions Identified from Administrative Health Data}

Eight studies provided estimates of the extent of medication-related adverse events identified using administrative health data, which can include events that caused the hospital admission or events that occurred during admission (Table 2) [34-41]. All studies identified medication-related hospital admissions using the International Classification of Diseases (ICD) coding. Using this method, between $1.3 \%$ and $4.6 \%$ (median $1.7 \%$, IQR $1.1 \%$ ) of patients were hospitalised due to medication-related adverse events.

Three studies provided estimates on the proportion of under-reporting of medication-related hospital admissions, ranging from $73 \%$ to $87 \%$ (median $82 \%$, IQR $7 \%$ ) (Table 2). There were 3 million unplanned admissions in Australia in 2019-2020 [13]. The median incidence of $1.7 \%$ with an under-reporting rate of $82 \%$ suggests approximately 280,000 hospital admissions annually are medication related.

\subsubsection{Triangulation of Results}

Triangulation of results assessed using chart review and coding from administrative data suggests that at 
Table 2 Incidence of medication-related hospital admissions assessed using International Classification of Diseases (ICD) coding (created by the authors)

\begin{tabular}{|c|c|c|c|c|}
\hline Study & $N$ & $N(\%)$ at admission & $\begin{array}{l}\text { Proportion } \\
\text { under-reported }\end{array}$ & $\begin{array}{l}N(\%) \text { on admis- } \\
\text { sion and during } \\
\text { stay }\end{array}$ \\
\hline Roughead et al. $1998[34]^{\mathrm{a}}$ & 952 & $15(1.6 \%)$ & $73 \%$ & NR \\
\hline Roughead et al. $1998[34]^{\mathrm{a}}$ & 172 & $4(2.3 \%)$ & $87 \%$ & NR \\
\hline Carroll et al.b 2003 [35] & 50,712 & $643(1.3 \%)$ & NR & $1389(2.7 \%)$ \\
\hline Hodgkinson et al. 2009 [36] & 12,414 & $157(1.3 \%)$ & NR & $412(3.3 \%)$ \\
\hline Hauck and Zhao ${ }^{\mathrm{b}} 2011$ [37] & 206,489 & NR & NR & $(3.4 \%)^{\mathrm{c}}$ \\
\hline Claydon-Platt et al. ${ }^{\mathrm{b}} 2012$ [38] & 9530 & $158(1.7 \%)$ & NR & $686(7.2 \%)$ \\
\hline Du et al. ${ }^{\text {b }} 2017$ [39] & 493,442 & NR & NR & $11,082(2.2 \%)$ \\
\hline $\begin{array}{l}\text { Parameswaran Nair et al. } 2018 \\
>65 \text { years [40] }\end{array}$ & 768 & $21(2.7 \%)$ & $82 \%$ & $50(6.5 \%)$ \\
\hline Mullan et al. ${ }^{\text {b }} 2019$ [41] & 228,165 & $10,555(4.6 \%)$ & NR & NR \\
\hline
\end{tabular}

N/A Not available

${ }^{\text {a }}$ This paper included data from two sources

${ }^{b}$ Limited to hospital records coding; no independent chart review

${ }^{\mathrm{c}}$ Actual number not available; percentage based on predicted rate for 2-day hospital stay least 250,000 hospital admissions annually in Australia are medication related, with the majority involving older adults. With an average cost per hospital stay of AUD\$5500 [15], this suggests the annual cost of medication-related hospital admission in Australia is at least AUD \$1.4 billion.

\subsection{Severity and Preventability of Adverse Medicine Events Associated with Hospitalisation or Admissions due to Medication-Related Problems}

Five studies that provided estimates on the extent of medication-related hospital admissions assessed the severity of the adverse medicine events associated with hospitalisation or admissions due to medication-related problems [21, 27, 29, 32, 33] (Table 3), while nine studies assessed preventability [20-23, 27, 29, 31-33] (Table 4). The number of studies that assessed severity was small, and the methods used to assess severity were different. The studies also involved different populations: two were in paediatric populations and two were in geriatric populations. Therefore, estimates of severity were not compared across studies. The majority of studies that assessed preventability used either the Schumock and Thornton [42] or Hallas criteria [43]. Preventability estimates suggest between 32\% and $87 \%$ (median $65 \%$, IQR $8.1 \%$ ) of medicine-related hospital admissions are potentially preventable (Table 4). Sensitivity analysis excluding the outlier [31] did not change the median estimate.

\section{Discussion}

Using methodological triangulation to examine the extent of medication-related hospital admissions in Australia, we estimated that 250,000 hospital admissions are medication related, with an associated cost of AUD $\$ 1.4$ billion annually. About one in five hospital admissions in older people are medication related. Of the studies that assessed preventability, approximately two-thirds of the medicationrelated hospital admissions were potentially preventable.

There is no single comprehensive data source to examine the extent or type of medication-related hospital admissions in Australia. This paper draws on data from many studies using different methods to assess the rate of medication-related hospital admissions in Australia. Estimates from chart review and administrative health data suggest that 250,000 hospital admissions are medication related. It should be noted that the estimated number of 250,000 medication-related hospital admissions annually does not include the number of medication-related emergency department presentations that did not lead to hospital admissions. We have previously estimated that an additional 400,000 presentations to emergency departments annually were likely to be due to medication-related problems [6].

Our estimated annual cost of medication-related hospital admissions of AUD $\$ 1.4$ billion is likely a conservative estimate. The actual cost is likely to be higher as the average costs of medication-related hospital admissions are higher than the average costs per hospital stay [44, 45]. Similarly, the estimate does not include the cost 
Table 3 Severity of adverse medicine events associated with hospitalisation or admissions due to medication-related problems (created by the authors)

\begin{tabular}{|c|c|c|c|c|c|}
\hline Study & Type of admission & $\begin{array}{l}\text { Total number of med- } \\
\text { icine-related problems } \\
\text { or admissions }\end{array}$ & Severity & $\begin{array}{l}\text { Method used to assess } \\
\text { severity }\end{array}$ & Definition of severity \\
\hline $\begin{array}{l}\text { Phillips et al. } 2014 \\
\text { [21] }\end{array}$ & Emergency admissions & 72 & $\begin{array}{l}\text { Moderate: } 65.3 \% \\
\text { Severe: } 34.7 \%\end{array}$ & $\begin{array}{l}\text { Modified Pearson clas- } \\
\text { sification }\end{array}$ & $\begin{array}{l}\text { Moderate: adverse } \\
\text { medicine event was } \\
\text { the major contributor } \\
\text { to hospital admis- } \\
\text { sion, with or without } \\
\text { requiring a change } \\
\text { in therapy or specific } \\
\text { treatment } \\
\text { Severe: life threatening, } \\
\text { caused permanent } \\
\text { damage or required } \\
\text { intensive care }\end{array}$ \\
\hline Easton et al. 1998 [32] & Paediatric admissions & 58 & $\begin{array}{l}\text { A: } 36.2 \% \\
\text { B: } 27.6 \% \\
\text { C: } 36.2 \% \\
\text { D: } 0 \%\end{array}$ & $\begin{array}{l}\text { Criteria developed by } \\
\text { study authors }\end{array}$ & $\begin{array}{l}\text { A: admitted up to } 24 \mathrm{~h} \\
\text { B: admitted for } 24-48 \mathrm{~h} \\
\text { C: admitted for }>48 \mathrm{~h} \\
\text { and/or requires admis- } \\
\text { sion to the intensive } \\
\text { care unit } \\
\text { D: permanent harm or } \\
\text { death }\end{array}$ \\
\hline Easton et al. 2004 [33] & Paediatric admissions & 127 & $\begin{array}{l}\text { A: } 49.6 \% \\
\text { B: } 21.3 \% \\
\text { C: } 29.1 \% \\
\text { D: } 0 \%\end{array}$ & $\begin{array}{l}\text { Criteria developed by } \\
\text { study authors }\end{array}$ & $\begin{array}{l}\text { Same as above-Easton } \\
\text { et al., } 1998 \text { [32] }\end{array}$ \\
\hline Chan et al. 2001 [29] & Geriatric admissions & 73 & $\begin{array}{l}\text { Moderate: } 84.3 \% \\
\text { Severe: } 15.7 \%\end{array}$ & $\begin{array}{l}\text { Modified Pearson clas- } \\
\text { sification }\end{array}$ & $\begin{array}{l}\text { Moderate: requiring } \\
\text { hospital admission, } \\
\text { change in therapy or } \\
\text { specific treatment } \\
\text { Severe: life-threatening, } \\
\text { caused permanent } \\
\text { damage or required } \\
\text { intensive care }\end{array}$ \\
\hline $\begin{array}{l}\text { Parameswaran Nair } \\
\text { et al. } 2017 \text { [27] }\end{array}$ & Geriatric admissions & 191 & $\begin{array}{l}\text { Moderate: } 97.9 \% \\
\text { Severe: } 2.1 \%\end{array}$ & Hartwig scale & $\begin{array}{l}\text { Moderate: require hospi- } \\
\text { tal admission, change } \\
\text { in therapy or specific } \\
\text { treatment } \\
\text { Severe: life-threatening, } \\
\text { caused permanent } \\
\text { damage or required } \\
\text { intensive care }\end{array}$ \\
\hline
\end{tabular}

associated with emergency department presentations that did not result in hospital admissions, or costs associated with medication errors, adverse medicine events or other medication-related problems occurring during hospital stay.

The rate of medication-related hospital admissions varied depending on the patient population or admission type. For example, the rate of medication-related hospital admissions was as high as $38 \%$ in the older population with unplanned admissions as compared to only $3-4 \%$ in the paediatric population. This is unsurprising considering older people are more likely to have many co-morbidities and take many medications; the high rate of medication-related hospital admissions in older people suggests that effective strategies must be taken to reduce medication-related harms. The most recent study published in 2017 involving the geriatric population and unplanned admissions found that $19 \%$ of unplanned admissions in older people were due to adverse medicine reactions [27]. In 56\% of cases, this occurred in a patient with a previous history of an adverse medicine reaction, and in just under $50 \%$ of cases, the cause was due to multiple medicines [27]. High rates of preventability were reported, with $87 \%$ considered preventable. Patients admitted due to adverse medicine reactions were at high risk of readmission due to an adverse reaction, with a follow-up study showing $13 \%$ of patients were readmitted due to an 
Table 4: Preventability of adverse medicine events associated with hospitalisation or admissions due to medication-related problems (created by the authors)

\begin{tabular}{|c|c|c|c|c|c|}
\hline Study & Type of admission & $\begin{array}{l}\text { Total number of } \\
\text { medicine-related prob- } \\
\text { lems or admissions }\end{array}$ & $\begin{array}{l}\text { Percentage con- } \\
\text { sidered definitely } \\
\text { avoidable }\end{array}$ & $\begin{array}{l}\text { Percentage considered } \\
\text { probably or possibly } \\
\text { avoidable }\end{array}$ & $\begin{array}{l}\text { Percentage considered } \\
\text { probably not or defi- } \\
\text { nitely unavoidable }\end{array}$ \\
\hline $\begin{array}{l}\text { Dartnell et al. } 1996 \\
\text { [20] }\end{array}$ & $\begin{array}{l}\text { Emergency admis- } \\
\text { sions }\end{array}$ & $55^{\mathrm{a}}$ & $5 \%$ & $60 \%$ & $35 \%$ \\
\hline $\begin{array}{l}\text { Phillips et al. } 2014 \\
\text { [21] }\end{array}$ & $\begin{array}{l}\text { Emergency admis- } \\
\text { sions }\end{array}$ & 72 & $54.2 \%$ & $11.1 \%$ & $34.7 \%$ \\
\hline Li et al. 2021 [22] & $\begin{array}{l}\text { Emergency admis- } \\
\text { sions }\end{array}$ & 496 & $28.8 \%$ & $32.1 \%$ & $39.1 \%$ \\
\hline $\begin{array}{l}\text { Sarkawi and Daud } \\
1995 \text { [23] }\end{array}$ & Medical admissions & $35^{\mathrm{a}}$ & $23 \%$ & $46 \%$ & $31 \%$ \\
\hline Easton et al. 1998 [32] & Paediatric admissions & $48^{\mathrm{a}}$ & N/A & $67 \%^{\mathrm{b}}$ & $29 \%^{\mathrm{b}}$ \\
\hline Easton et al. 2004 [33] & Paediatric admissions & 81 & $46.9 \%^{\mathrm{b}}$ & N/A & $30.9 \%^{\mathrm{b}}$ \\
\hline Ng 1996 [31] & Geriatric admissions & 31 & $3 \%$ & $29 \%$ & $68 \%$ \\
\hline Chan et al. 2001 [29] & Geriatric admissions & 73 & $53.4 \%$ & $23.3 \%$ & $23.3 \%$ \\
\hline $\begin{array}{l}\text { Parameswaran Nair } \\
\text { et al. } 2017 \text { [27] }\end{array}$ & Geriatric admissions & 328 & $87.2 \%^{\mathrm{b}}$ & & N/A \\
\hline
\end{tabular}

N/A not available

${ }^{\mathrm{a}}$ Overdose excluded

${ }^{b}$ Percentage does not add up to $100 \%$ because authors either did not explicitly state that the remaining cases were not preventable or the authors stated they were unable to determine preventability for some cases

adverse reaction in the 12 months following their first admission due to an adverse reaction [46]. More intensive and proactive monitoring of medicine effects is needed to reduce the frequency of admissions and re-admissions that are due to medication-related problems. Patients admitted for medication-related problems should have active discharge plans and follow-up within 2 weeks of discharge (either in person or via telehealth) to prevent re-admission.

Medication-related hospital admissions still represent a serious health issue and are associated with significant costs to the Australian healthcare system. There is a need to better integrate existing strategies (e.g. post-discharge services) into current workflows as well as to test and implement new strategies to reduce medication-related hospital admissions. National implementation of the My Health Record means that healthcare professionals including community pharmacists have access to comprehensive medication histories as well as clinical biomarkers such as renal function, liver function, electrolytes and international normalised ratio (INR) results. Access to complete medication histories and clinical biomarkers will provide healthcare professionals in the community setting the opportunity to proactively intervene to both document and reduce medication-related problems during patient encounters. Australia's Medical Research Future Fund (MRFF), which is now worth AUD\$20 billion, also provides the opportunity to test new strategies to improve medicine use and health outcomes [47].

\subsection{Strengths and Limitations}

Our study included all Australian studies published between 1998 and 2021 that estimated the rate of medication-related hospital admissions. The large number $(n=17)$ of Australian studies that assessed medicationrelated problems using the gold standard method of medication chart review assessed by an independent multidisciplinary clinical panel, coupled with the very similar estimates found using coding from administrative data, means that our national estimate on the extent and cost of medication-related hospital admissions should be considered reliable, albeit, a conservative estimate. Our study is limited by the exclusion of studies that reported the odds but not the frequency of medication-related hospital admissions. Both methods used to assess medication-related problems (i.e. chart review and administrative data coding) each have their limitations. For example, medication chart reviews may be conducted using inaccurate or incomplete documentation, or the information may be poorly recorded. Limitations with the use of administrative database include wrongly coded data, incomplete information and subjective judgement of the assessor during coding. These limitations mean that the rate estimates may not be accurate. Finally, our paper only included studies conducted in Australia, and therefore, our national estimates cannot be extrapolated to other countries. 


\section{Conclusion}

Medication safety remains a significant challenge to the Australian healthcare system. We estimate that 250,000 hospital admissions in Australia are medication related, with an annual cost of AUD\$1.4 billion to the healthcare system. Approximately half of the admissions are potentially preventable. Strategies to proactively monitor and prevent problems with medicine use need to be implemented to reduce medication-related hospital admissions in Australia.

Supplementary Information The online version contains supplementary material available at https://doi.org/10.1007/s40264-021-01144-1.

\section{Declarations}

Funding Open Access funding enabled and organized by CAUL and its Member Institutions. No specific funding was received for the conduct of this study.

Conflict of interest RL is supported by a National Health and Medical Research Council (NHMRC) Early Career Fellowship (APP1156368). All other authors declare no conflicts of interest.

Ethics approval Not applicable.

Consent to participate Not applicable.

Consent for publication Not applicable.

Availability of data and material Data sharing is not applicable to this article as no datasets were generated or analysed during the current study.

Code availability Not applicable.

Author contributions Conceptualisation: RL and EER. Literature search and data extraction: RL and EER. Analysis and interpretation of data: All authors. Drafting of the manuscript: All authors. Critical revision of the manuscript for important intellectual content: All authors. All authors read and approved the final version.

Open Access This article is licensed under a Creative Commons Attribution-NonCommercial 4.0 International License, which permits any non-commercial use, sharing, adaptation, distribution and reproduction in any medium or format, as long as you give appropriate credit to the original author(s) and the source, provide a link to the Creative Commons licence, and indicate if changes were made. The images or other third party material in this article are included in the article's Creative Commons licence, unless indicated otherwise in a credit line to the material. If material is not included in the article's Creative Commons licence and your intended use is not permitted by statutory regulation or exceeds the permitted use, you will need to obtain permission directly from the copyright holder. To view a copy of this licence, visit http://creativecommons.org/licenses/by-nc/4.0/.

\section{References}

1. Australian Institute of Health and Welfare. Medicines in the health system. 2020. https://www.aihw.gov.au/reports/australias-health/ medicines-in-the-health-system. Cited 6 Oct 2021.

2. Australian Bureau of Statistics. National Health Survey: Persons accessing Pharmaceutical Benefits Scheme subsidised prescriptions, 2014-15. 2020. https://www.abs.gov.au/statistics/research/ national-health-survey-persons-accessing-pharmaceutical-benef its-scheme-subsidised-prescriptions-2014-15. Cited 6 Oct 2021.

3. Australian Institute of Health and Welfare. Health expenditure Australia 2018-2019. 2020. https://www.aihw.gov.au/reports/ health-welfare-expenditure/health-expenditure-australia-201819/contents/data-visualisation. Cited 6 Oct 2021.

4. Strand LM, et al. Drug-related problems: their structure and function. DICP. 1990;24(11):1093-7.

5. Edwards IR, Aronson JK. Adverse drug reactions: definitions, diagnosis, and management. Lancet. 2000;356(9237):1255-9.

6. Pharmaceutical Society of Australia. Medicine safety: take care. 2019. https://www.psa.org.au/wp-content/uploads/2019/01/PSAMedicine-Safety-Report.pdf. Cited 28 Oct 2019

7. Pharmacy Programs Administrator. Home medicines review. 2018. https://www.ppaonline.com.au/programs/medication-manag ement-programs/home-medicines-review. Cited 30 Aug 2021

8. de Vries EN, et al. The incidence and nature of in-hospital adverse events: a systematic review. Qual Saf Health Care. 2008;17(3):216-23.

9. Kapoor A, et al. Adverse events in long-term care residents transitioning from hospital back to nursing home. JAMA Intern Med. 2019;179(9):1254-61.

10. Australian Council on Safety and Quality in Health Care, Second national report on improving patient safety: improving medication safety. 2002, Australian Council on Safety and Quality in Health Care: Canberra.

11. Roughead E, Semple S. Medication safety in acute care in Australia: where are we now? Part 1: a review of the extent and causes of medication problems 2002-2008. Aust N Zeal Health Policy. 2009;6(1):18.

12. Roughead L, Semple S, Rosenfeld E. Literature Review: Medication Safety in Australia. 2013. https://www.safetyandquality. gov.au/sites/default/files/migrated/Literature-Review-Medic ation-Safety-in-Australia-2013.pdf. Cited 28 Oct 2019

13. Australian Institute of Health and Welfare. Admitted patients. 2021. https://www.aihw.gov.au/reports-data/myhospitals/secto rs/admitted-patients. Cited 12 Oct 2021

14. Denzin NK. The research act: a theoretical introduction to sociological methods. New Jersey: Transaction Publishers; 1970.

15. Australian Institute of Health and Welfare. Spending on admitted patients. 2019. https://www.aihw.gov.au/reports-data/myhos pitals/intersection/spending/apc. Cited 12 Oct 2021

16. Tukey JW. Exploratory data analysis. Vol 2. Reading, Mass; 1977.

17. Gleeson CA. Adverse drug reactions causing hospital admissions. Sydney: University of Sydney; 1988.

18. Larmour I, et al. A prospective study of hospital admissions due to drug reactions. Aust J Hosp Pharm. 1991;21:90-5.

19. Galbraith K. Is there a role for a clinical pharmacist in the emergency department? In: Victorian College of Pharmacy. 1993, Monash University: Melbourne.

20. Dartnell JG, et al. Hospitalisation for adverse events related to drug therapy: incidence, avoidability and costs. Med J Aust. 1996;164(11):659-62.

21. Phillips AL, et al. Hospital admissions caused by adverse drug events: an Australian prospective study. Aust Health Rev. 2014;38(1):51-7. 
22. Li R et al. (2021) Prevalence, characteristics, and reporting of adverse drug reactions in an Australian hospital: a retrospective review of hospital admissions due to adverse drug reactions. Expert Opin Drug Saf. 2021: 1-8

23. Sarkawai H, Daud TM A study of drug induced illness as a contributor to hospital admissions. Royal Adelaide Hospital: Adelaide; 1995.

24. Stanton LA, et al. Drug-related admissions to an Australian hospital. J Clin Pharm Ther. 1994;19(6):341-7.

25. Leishman S, Vial JH. Drug related admissions to the Royal Hobart Hospital. in Australian Society of Clinical and Experimental Pharmacology (ASCEPT). 1998. ASCEPT.

26. Wong ME, et al. Drug-related hospital admissions of geriatric patients. Aust J Hosp Pharm. 1993;23:75.

27. Parameswaran Nair N, et al. Adverse drug reaction-related hospitalizations in elderly australians: a prospective crosssectional study in two tasmanian hospitals. Drug Saf. 2017;40(7):597-606.

28. Harding AM. A snapshot of admissions to an acute medical unit for the aged. Aust J Hosp Pharm. 1998;28:359-60.

29. Chan M, Nicklason F, Vial JH. Adverse drug events as a cause of hospital admission in the elderly. Intern Med J. 2001;31(4):199-205.

30. Atkin PA, et al. Prevalence of drug-related admissions to a hospital geriatric service. Aust J Ageing. 1994;13:17-21.

31. Ng D. Adverse medication-related events and unplanned admissions to an acute care general teaching hospital. Adelaide: University of South Australia; 1996.

32. Easton KL, et al. The incidence of drug-related problems as a cause of hospital admissions in children. Med J Aust. 1998;169(7):356-9.

33. Easton KL, Chapman CB, Brien JA. Frequency and characteristics of hospital admissions associated with drug-related problems in paediatrics. Br J Clin Pharmacol. 2004;57(5):611-5.

34. Roughead E, et al. Coding drug-related admissions in medical records: is it adequate for monitoring the quality of medication use? Aust J Hosp Pharm. 1998;28(1):7-12.

35. Carroll R, McLean J, Walsh M. Reporting hospital adverse events using the Alfred Hospital's morbidity data. Aust Health Rev. 2003;26(2):100-5.
36. Hodgkinson MR, Dirnbauer NJ, Larmour I. Identification of adverse drug reactions using the ICD-10 Australian modification clinical coding surveillance. J Pharm Pract Res. 2009;39(1):19-23.

37. Hauck K, Zhao X. How dangerous is a day in hospital? A model of adverse events and length of stay for medical inpatients. Med Care. 2011;49(12):1068-75.

38. Claydon-Platt K, Manias E, Dunning T. Medication-related problems occurring in people with diabetes during an admission to an adult teaching hospital: a retrospective cohort study. Diabetes Res Clin Pract. 2012;97(2):223-30.

39. Du W et al. Diagnosis-based and external cause-based criteria to identify adverse drug reactions in hospital ICD-coded data: application to an Australia population-based study. Public Health Res Pract. 2017. 27(2)

40. Parameswaran Nair N, et al. Prospective identification versus administrative coding of adverse drug reaction-related hospitalizations in the elderly: a comparative analysis. Pharmacoepidemiol Drug Saf. 2018;27(11):1281-5.

41. Mullan J, et al. Hospitalisation for medication misadventures among older adults with and without dementia: a 5-year retrospective study. Aust J Ageing. 2019;38(4):e135-41.

42. Schumock G, Thornton J. Focusing on the preventability of adverse drug reactions. Hosp Pharm. 1992;27(6):538-538.

43. Hallas J, et al. Drug related hospital admissions: the role of definitions and intensity of data collection, and the possibility of prevention. J Intern Med. 1990;228(2):83-90.

44. Slight SP, et al. The national cost of adverse drug events resulting from inappropriate medication-related alert overrides in the United States. J Am Med Inform Assoc. 2018;25(9):1183-8.

45. Leendertse AJ, et al. Preventable hospital admissions related to medication (HARM): cost analysis of the HARM study. Value Health. 2011;14(1):34-40.

46. Parameswaran Nair N, et al. Repeat adverse drug reaction-related hospital admissions in elderly Australians: a retrospective study at the royal Hobart hospital. Drugs Aging. 2017;34(10):777-83.

47. Australian Government Department of Health. Medical research future fund. 2021. https://www.health.gov.au/initiatives-and-progr ams/medical-research-future-fund. Cited 20 Oct 2021 